Editorial

\title{
Gender Differences in Healthy Lifestyle Practices and Well-Being in Preventing Noncommunicable Diseases
}

\author{
Nagaraj Kondagunta ${ }^{1}$ \\ ${ }^{1}$ Department of Community Medicine, SVIMS, Sri Padmavathi \\ Medical College for Women, Tirupati, Andhra Pradesh, India
}

Ind J Car Dis Wom 2021;6:6-7.

Lifestyle practices and well-being at individual level and population level have very important bearing on occurrence of noncommunicable diseases including cardiovascular diseases. Dietary habits (which include intake of fruits and vegetables and fast foods), physical activity, tobacco, and alcohol use are different lifestyle practices to be assessed according to World Health Organization STEPwise approach to noncommunicable disease surveillance guidelines. ${ }^{1}$ Inadequate diet and insufficient physical activity together as a risk factor has synergistic effect in contributing to occurrence of noncommunicable diseases. Lifestyle is mainly conditioned by factors related to family, economy, education, and social environment, and these factors influence lifestyle progressively over a period of time starting early in life. In this context, gender differences are to be viewed as one of the main determinants of lifestyle and of population health. There is a need to understand the difference between terms "gender" and "sex." Gender refers to socially developed characteristics of women and men in response to their environment and sex refers to biological aspect of an individual. ${ }^{2}$

In total, $65 \%$ female deaths globally are related to noncommunicable diseases which is going to be a major concern. Cardiovascular diseases accounts for $33.2 \%$ of female deaths ahead of infectious and parasitic diseases (13.9\%) and cancers (13.0\%) as cause of death. ${ }^{2}$ It is significant to examine the gender differences as lifestyle practices and health status are affected by sex-specific biological factors and gender-related social factors.

Life course approach is considered as best approach in the prevention of noncommunicable diseases and sex and gender analysis should be part of this approach. The ratio of incidence of acute coronary syndrome in men and women has decreased from 23:1 from 1967 to 4:1 in 2007 in Kerala. Restricted outdoor activity by girls and women which lowers endogenous vitamin D synthesis and further leads to low skeletal mass and high body fat composition, which may explain this difference and so lifestyle approach directed toward women is required today. ${ }^{3}$

There is no standard definition of well-being. There are two approaches of well-being need to be studied which are termed as Hedonia and Eudaimonia. Hedonia denotes happiness, pleasure attainment, and life satisfaction, whereas eudaimonia refers to deeper form of well-being concerned with meaning and realization of individuals true potential (e.g., purpose in life and personal growth).

The primary approaches to conceptualize well-being includes hedonic approach eudaimonic approach, quality of life approach, and wellness approach. There are many instruments (both objective and subjective) available to assess well-being which may be used appropriately in research.

Positive well-being has protective effect against cardiovascular disease risk factors incident cardiovascular diseases, secondary cardiovascular events, and mortality according to evidence based on different studies. ${ }^{4}$ Health behaviors such as physical activity, sleep, diet, nonsmoking, and medication adherence are responsible for the association between positive well-being and cardiovascular diseases. Reduced stress reactivity, adaptive coping skills and better immune, neuroendocrine, and cardiovascular functioning are associated with positive well-being. ${ }^{4}$ There are gaps in knowledge, lack of availability of prospective studies on mechanistic pathway in relation between positive well-being, and occurrence of cardiovascular diseases. ${ }^{4,5}$

The article entitled "Gender-wise comparative assessment of lifestyle patterns and well-being status among health care employees at a tertiary care hospital" published in this issue of the journal is relevant and significant as very few studies have been done on the importance of gender wise assessment of lifestyle practices and well-being in India. The well-being assessment tool described in the article

\author{
Address for correspondence \\ Nagaraj Kondagunta, MD, \\ Department of Community Medicine, \\ SVIMS, Sri Padmavathi Medical College \\ for Women, Tirupati, Andhra Pradesh, \\ 517507, India \\ (e-mail: sanjurajrekha@yahoo.com).
}

DOI https://doi.org/ 10.1055/s-0041-1726612

published online March 30, 2021
(C)2021. Women in Cardiology and Related Sciences.

This is an open access article published by Thieme under the terms of the Creative Commons Attribution-NonDerivative-NonCommercial-License, permitting copying and reproduction so long as the original work is given appropriate credit. Contents may not be used for commercial purposes, or adapted, remixed, transformed or built upon. (https://creativecommons.org/licenses/by-nc-nd/4.0/).

Thieme Medical and Scientific Publishers Pvt. Ltd. A-12, 2nd Floor, Sector 2, Noida-201301 UP, India 
which included physical health, social health, mental health, intellectual health, and spiritual health components is comprehensive and acceptable. However, lifestyle practices like eating vegetables and fruits, smoking, and alcohol was not covered in the study. The initiative which has been proposed in the article to improve adoption of yoga and meditative practices among employees is very positive and if implemented well would improve well-being status paving way for prevention of noncommunicable diseases among employees working in tertiary care hospitals.

Further research is required in India and globally to understand gender wise differences in life style practices and well-being among employees in different workplace settings. This is should later pave way to successful implementation of work place wellness programs for noncommunicable diseases to be prevented in different occupational settings in India and abroad.

Conflict of Interest

None declared.

\section{References}

1 Bonita R, de Courten M, Dwyer T, Jamrozik K, Winkelmann R. Surveillance of risk factors for noncommunicable diseases: The WHO STEP wise approach. Summary. Geneva: World Health Organization; 2001

2 Varì R, Scazzocchio B, D’Amore A, Giovannini C, Gessani S, Masella R. Gender-related differences in lifestyle may affect health status. Ann Ist Super Sanita 2016;52(2):158-166

3 Sivasankaran S, Thankappan KR. Prevention of noncommunicable diseases requires a life course approach: a case study from Kerala. Indian J Med Res 2013;137(5):874-877

4 Sin NL. The protective role of positive well-being in cardiovascular disease: review of current evidence, mechanisms, and clinical implications. Curr Cardiol Rep 2016;18(11):106

5 Gbadamosi MA, Tlou B. Modifiable risk factors associated with non-communicable diseases among adult outpatients in Manzini, Swaziland: a cross-sectional study. BMC Public Health 2020;20(1):665 